\title{
FLIGHT INSTRUCTORS' PERCEPTIONS OF PILOT BEHAVIOUR RELATED TO GENDER
}

Author:

Leopold P. Vermeulen ${ }^{1}$

\section{Affiliation:}

${ }^{1}$ Department of Human Resource Management,

University of Pretoria,

South Africa

\section{Correspondence to:}

Leopold P. Vermeulen

e-mail:

leo.vermeulen@up.ac.za

\section{Postal address:}

PO Box 31647, Totiusdal, 0134, South Africa

\section{Keywords:}

flight instructors; gender; flying proficiency; safety orientation; pilot behaviour

\section{Dates:}

Received: 24 Feb. 2009

Accepted: 07 June 2009

Published: 06 Aug. 2009

How to cite this article: Vermeulen, L.P. (2009).

Flight instructors' perceptions of pilot behaviour related to gender. SA Journal of Industrial Psychology/SA

Tydskrif vir Bedryfsielkunde, 35(1), Art. \#819, 8 pages.

DOI: 10.4102/sajip.35i1.819

This article is available at: http://www.sajip.co.za

(c) 2009. The Authors. Licensee: OpenJournals Publishing. This work is licensed under the Creative Commons Attribution License.

\section{INTRODUCTION}

In the last decade, new South African government and labour policies that encourage more women to become aviators have evolved. However, even though women have been aviators for almost as long as men, aviation is still largely a male-dominated sphere. Stereotypically masculine traits are more often perceived to be desirable in pilots than stereotypically female characteristics and a career in aviation is still not deemed as feasible for women as for men (Helmreich \& Merrit, 1998; Sitler, Turney \& Wulle, 1996). Although women have proven their worth and ability, the prejudices implicit in comments such as 'If God wanted women to fly, he would have painted the sky pink' and 'A woman in the cockpit is one less in the kitchen' still survive. As soon as questions are raised about whether women should take up flying in a professional capacity or whether they should take up combat-aviation roles, many people, particularly men, display negative attitudes with regard to such suggestions (Barker, 1999; Davey \& Davidson, 2000).

Davey and Davidson (2000) pointed out that the first women to join airlines in Europe experienced problems in respect of sexism, harassment, high visibility and isolation. These authors stated that many female pilots working for European commercial-aviation companies reported that gender-related obstacles caused them to experience difficulties and distress. These women encountered strong prejudices and preconceptions concerning their abilities and women's suitability for a career as professional pilots. Although the extent of these difficulties has declined over time, women's experience of dealing with sexism and prejudice continues (Davey \& Davidson, 2000). One female captain with a large European airline expressed concern that male captains expected less of female copilots and were more reluctant to give them necessary corrective feedback. She believed that the flying standards of female pilots were being eroded (Johnson, 1995, p. 191). If she is right, this has important implications for flight performance and aviation safety.

A topic of intense debate and continuing interest is whether male and female pilots differ in respect of their behaviour related to their flight performance and aviation safety. Regrettably, a review of the available literature reveals that many articles about female pilots are only quasi-scientific and are based on anecdotal reports. These articles reflect an incomplete and sometimes misleading picture of the acceptance (or lack of acceptance) of female pilots in commercial aviation (Davey \& Davidson, 2000, p. 195). Very few scientific studies about gender issues in aviation have been published so far, with the exception of the scientific studies by Baker, Lamb, Grabowski, Rebok and Li (2001), Barker (1999), Bartsch and Hawkins (1996), Davey and Davidson (2000), Fischer and Orasanu (1999), Johnson (1995), King, Retzlaff and McGlohn (1997), McCarthy and McGinn (1995), Sitler (2004), Sitler et al. (1996), Turney (1995) and Turney and Bishop (2004). These articles provide some evidence to suggest that there are differences between male and female pilots with regard to factors such as ability, learning, confidence, communication structure, interpersonal relationships, leadership style, flight performance and the type of pilot error involved in general aviation crashes.

Researchers at the Georgia Institute of Technology (GIT) and the Bloomberg School of Public Health have examined the nature of gender differences in aviation. According to the study at GIT, there are gender, social and cultural differences in the ways that airline crews communicate in both low-risk and highrisk flight situations. The study, funded by the National Aeronautics and Space Administration's Ames Laboratory, found that female pilots tend to use more two-part utterances than males: they state the problem and then give a command or suggestion to their copilot (Fischer \& Orasanu, 1999).

Baker et al. (2001) at the Bloomberg School of Public Health found that male pilots flying general aviation (private) aircraft in the USA are more likely to crash due to inattention or flawed decision-making, while female pilots are more likely to crash because they mishandle the aircraft. They also found that loss of control on landing or take-off was the most common source of crashes for both sexes, leading to $59 \%$ of crashes by female pilots and $36 \%$ of crashes by male pilots. Mechanical failure, running out of fuel and landing the plane with the landing gear up were among the problems more likely to occur with males, while stalling was more likely to occur with females. However, McFadden (1996) found no difference between the pilot-error accident rates of male and female airline pilots. According to him, gender does not appear to be a risk factor for accidents when exposure to flying opportunity is controlled. 
In a qualitative study of the perceptions of 15 male and female airline, corporate and military pilots, Turney (1995) found a number of gender-based differences. The pilots whom she interviewed generally expressed an awareness of differences between men and women pilots' learning and leadership styles. Male pilots

... were reported to be more task-oriented and to exhibit more confidence as crewmembers than women pilots. Women pilots were reported to be better communicators and to exhibit more sensitivity to people than male pilots and to be good negotiators. Women were also reported to work harder at learning technical information to compensate for a possible lack of a background in mechanical training.

(Turney, 1995, p. 264)

Turney (1995) indicated that barriers to women's integration into flight crews and in areas of conflict included a lack of understanding of gender differences, a 'macho' pilot image, quota hiring, the possibility of pregnancy, leadership roles, attitudes that hold that only males are professionals and the view that mistakes made by women are gender weaknesses rather than personal mistakes. Both sexes reported that women should strengthen their abilities to demonstrate confidence and forcefulness. However, misunderstandings and conflict arose when female pilots were perceived to act in a manner that was regarded as 'male'. This included displaying assertive behaviour using demeaning language and showing a forceful demeanour (Turney, 1995, pp. 264-265).

Because perceptions based on gender differences (real or alleged) have a pervasive and powerful influence on behaviour, it is important to manage gender diversity properly, particularly in the aviation field. Davey (2004, p. 645) recommended that human-factor training be used to 'encourage more positive attitudes towards female pilots, as female pilots are deeply sceptical of the benefits of the equal opportunity policies' of airlines. If stereotypes, negative attitudes and prejudices are not addressed in a formal setting, such as crew resource management (CRM) and human-factor training, they can, unfortunately, lead to problems in a multi-crew environment. To ensure optimal performance, every member of the crew must be supported and directed to adjust her or his stereotypes, attitudes and behaviour to meet the demands of a two-gender workplace (Sitler et al., 1996; Turney, 1995).

Today, many airlines, with considerable encouragement from agencies such as the International Civil Aviation Organization, the Federal Aviation Administration and other civil-aviation authorities emphasise the management of human-factor issues by means of human-factor training and CRM courses. The courses deal with, inter alia, crew members' perceptions, attitudes and forms of behaviour (teamwork, decision-making and situational awareness) that might significantly reduce or enhance flightcrew performance and aviation safety.

Research by Severin and Antersijn (1998) into the quality and effectiveness of CRM and human-factor training has provided ample evidence that the success of such programmes (especially where behaviour, attitudes and interpersonal skills are concerned) depends strongly on the skills, attitudes and personality of the trainers and instructors. Instructors influence their students' learning, attitudes, values and behaviour either directly or indirectly (Moore, Lehrer \& Telfer, 1997; Severin \& Antersijn, 1998). In terms of occupational socialisation, instructors are one of the most significant influences in shaping student pilots' expectations, standards and biases. According to Frazier (2000, p. xvii), it is instructors who develop the foundation of airmanship in each new student, who model students' perceptions and behaviour (positive and negative) and, 'in a very real sense, create clones of themselves to send out into the aviation community' (ibid., p. xvii).

Little research has thus far been undertaken on instructors' attitudes towards female pilots. Davey (2004) examined the discourse between instructors and female trainee pilots at a flying college in Europe. In general, the instructors perceived female trainee pilots to be more responsible and less inclined to take risks than male pilots. Respondents referred to female trainee pilots as being more sympathetic and mature and as people with whom others could discuss their problems. Davey (2004) admitted that these comments reflect stereotypical ideas about females. Other researchers might classify these comments as reflecting 'benevolent sexism', that is 'a subjectively favourable, chivalrous ideology that offers protection and affection to women who embrace conventional roles' (Glick \& Fiske, 2001, p. 109). Davey (2004, p. 644) also stated that the instructors viewed female cadet pilots more positively when they 'conform[ed] to feminine ideals in terms of their body image, sexuality, and behaviour (for example, by acting as confidants)'. Understanding the dynamics of perceptions about female pilots is thus more complex than merely accepting the now clichéd truism that 'men are from Mars and women are from Venus' (Gray, 1992, p.1).

Based on the above discussion of gender issues in aviation and the importance of instructors as trainers, educators and rolemodels, several questions arise about South African instructors' perceptions of gender-related pilot behaviour. For example, do instructors hold different perceptions regarding female pilots compared to the perceptions held by commercial pilots? Do instructors and commercial pilots hold positive or negative perceptions about female pilots? Do instructors who have completed a CRM programme hold different perceptions with regard to female pilots than do those of their colleagues who have not attended a CRM programme?

Questions such as these guided the choice of the objectives of the present study and the formulation of the hypotheses.

The primary aims of the study were to compare flight instructors' and commercial pilots' perceptions of genderrelated pilot behaviour and to explore the relationship between the biographical characteristics of the instructors and their perceptions of female-pilot behaviour.

The following general hypotheses were formulated:

- $\mathrm{H}_{1}$ :There are significant differences between the perceptions of gender-related pilot behaviour held by flight instructors and those held by a comparable group of commercial pilots.

- $\mathrm{H}_{2}$ :There are significant differences between the perceptions of gender-related pilot behaviour held by flight instructors with CRM training and those held by flight instructors without exposure to CRM.

- $\mathrm{H}_{3}$ : There are significant relationships between perceived gender-related pilot behaviour and the following characteristics of flight instructors: instructor rating, level of education, age, instructional hours and total flying hours.

\section{RESEARCH DESIGN}

\section{Research approach}

In order to achieve the study objectives and to test the hypotheses, a quantitative-research approach based on the positivist paradigm was followed. A cross-sectional survey was conducted using a structured questionnaire to collect the research data from two samples. The data were analysed in accordance with the basic associational design and two comparative designs, as suggested by Morgan and Griego (1998, pp 77-86). The associational design was used to determine the strength of the relationship between sample identity and the biographical characteristics of the participants. The 'between independent groups design' was used, firstly, to establish whether the samples were homogeneous in terms of specific biographical characteristics and, secondly, to compare flight instructors' and commercial pilots' perceptions 
TABLE 1

Biographical characteristics of the two samples

\begin{tabular}{|c|c|c|c|c|}
\hline \multirow[t]{2}{*}{$\begin{array}{l}\text { BIOGRAPHICAL } \\
\text { CHARACTERISTICS }\end{array}$} & \multicolumn{2}{|c|}{$\begin{array}{c}\text { INSTRUCTORS } \\
(93) \\
\end{array}$} & \multicolumn{2}{|c|}{$\begin{array}{c}\text { PILOTS } \\
(93)\end{array}$} \\
\hline & $\mathbf{N}$ & $\%$ & $\mathbf{N}$ & $\%$ \\
\hline \multicolumn{5}{|l|}{ Gender } \\
\hline Male & 84 & 90.3 & 88 & 94.6 \\
\hline Female & 9 & 9.7 & 5 & 5.4 \\
\hline \multicolumn{5}{|l|}{ Education } \\
\hline High school & 52 & 55.9 & 66 & 71.0 \\
\hline Technical diploma & 20 & 21.5 & 14 & 15.0 \\
\hline Degree & 21 & 22.6 & 13 & 14.0 \\
\hline \multicolumn{5}{|l|}{ Licence } \\
\hline Fixed-wing CPL & 71 & 76.3 & 67 & 72.0 \\
\hline Fixed-wing ATPL & 22 & 23.7 & 26 & 28.0 \\
\hline \multicolumn{5}{|l|}{ CRM training } \\
\hline Yes & 52 & 55.9 & 81 & 87.1 \\
\hline No & 41 & 44.1 & 12 & 12.9 \\
\hline \multicolumn{5}{|l|}{ Instructors' rating } \\
\hline Grade 3 & 36 & 38.7 & - & - \\
\hline Grade 2 & 53 & 57.0 & - & - \\
\hline Grade 1 & 4 & 4.3 & - & - \\
\hline \multicolumn{5}{|l|}{ Nature of instruction } \\
\hline Full time & 78 & 83.9 & - & - \\
\hline Part time & 15 & 16.1 & - & - \\
\hline
\end{tabular}

of gender-related pilot behaviour. The 'between groups multifactorial design' was used to explore the relationship between the biographical characteristics of the flight instructors and their perceptions of female pilots' behaviour. The research design and research proposal were scrutinised by an ethics committee and were approved.

\section{Research method \\ Participants}

The subjects fell into two groups. The first was a purposive sample of 93 flight instructors. The second was a convenience sample of 93 commercial pilots who were used as a control group. The sample of 93 instructors came from 65 different flighttraining schools, representing a cross-section of $48.1 \%$ of the 135 fixed-wing flight schools accredited by the South African Civil Aviation Authority (SACAA). The 93 commercial pilots were employed at 14 aviation organisations, where they operated fixed-wing aircraft for business and military purposes.

The demographics of the participants from both samples are summarised in Table 1.

The sample population for this study was predominately male. Of the participants, $172(92.5 \%)$ were male and $14(7.5 \%)$ were female. These numbers reflect the current low proportional representation of female pilots $(6.1 \%)$ engaged in commercial aviation and flight instruction in South Africa (SACAA, 2007).

The average age of the participants was 33.59 years. Most of the oldest participants were flight instructors, with an average age of 35.16 years $(\mathrm{SD}=12.84)$. The youngest group consisted of commercial pilots, with an average age of 31.94 years $(\mathrm{SD}=$ 9.31). The mean flying time of the sample population was 3796.48 hours. The participants' flying experience ranged between one year and 45 years, with an average of 11.54 years. The average flying time and years of experience for the instructors were 4180.38 hours $(\mathrm{SD}=5375.74)$, and 12.34 years $(\mathrm{SD}=11.54)$ and 3416.71 hours $(\mathrm{SD}=3714.19)$ and 10.67 years $(\mathrm{SD}=9.60)$ for the commercial pilots.

The instructors had been instructing trainee pilots for an average of 7.31 years $(S D=9.86)$, with an average of 2006.54 instructional hours $(\mathrm{SD}=3001.54)$. Most of the instructors $(83.9 \%)$ were involved in instruction full time; of these, $71(76.3 \%)$ had a commercial pilot's licence and $22(23.7 \%)$ an airline-transport pilot's licence. A total of $75 \%$ were grade-two instructors.

The instructors were relatively well educated: of the respondents, $21.7 \%$ held a technical diploma and $22.8 \%$ had been awarded at least a bachelor's degree. The participants were also relatively evenly split between instructors with CRM training (55.9\%) and instructors without CRM training (44.1\%).

\section{Measuring instrument}

The Aviation Gender Attitude Questionnaire (AGAQ) was used as a survey instrument. The AGAQ was developed by Vermeulen and Wilson (2002) using a sample of 544 airline, commercial, military and general aviation pilots. The questionnaire consists of two sections. Section A contains biographical data and Section B contains statements relating to flying proficiency and safety orientation. Wilson (2004) provided detailed information regarding the development of the AGAQ and its psychometric properties.

Initially, the AGAQ consisted of 72 items. After two rounds of exploratory factor analyses, a two-factor solution comprising 43 items was established (Vermeulen \& Wilson, 2002). Scales were created for each of the two factors and they were labelled according to the items with the highest loadings. The two scales were named 'flying proficiency' and 'safety orientation'.

- 'Flying proficiency' consists of 31 items measuring perceptions related to decision-making in flying, the speed at which concepts related to flying are understood, general piloting skills and the pilots' comfort level with regard to stick-and-rudder controls

- 'Safety orientation' consists of 12 items measuring perceptions related to the level of risk-taking among pilots of a particular gender, pilots' safety consciousness, attention to detail and prudence.

TABLE 2

Descriptive statistics of the responses of the flight instructors and pilots on the two scales of the AGAQ

\begin{tabular}{|c|c|c|c|c|}
\hline \multirow[t]{2}{*}{ DESCRIPTIVE STATISTICS } & \multicolumn{2}{|c|}{$\begin{array}{c}\text { INSTRUCTORS } \\
\mathrm{n}=93\end{array}$} & \multicolumn{2}{|c|}{$\begin{array}{c}\text { PILOTS } \\
\mathrm{n}=93\end{array}$} \\
\hline & FLYING PROFICIENCY & SAFETY ORIENTATION & FLYING PROFICIENCY & SAFETY ORIENTATION \\
\hline Minimum & 34.000 & 20.000 & 37.000 & 24.000 \\
\hline Maximum & 151.000 & 54.000 & 152.000 & 51.000 \\
\hline Mean & 103.452 & 38.828 & 97.011 & 37.172 \\
\hline SD & 18.720 & 6.355 & 21.079 & 6.293 \\
\hline Skewness & -0.147 & -0.333 & -0.324 & -0.110 \\
\hline Sk-error & 0.250 & 0.250 & 0.250 & 0.250 \\
\hline Kurtosis & 1.507 & -0.277 & 0.788 & -0.607 \\
\hline Ku-error & 0.495 & 0.495 & 0.495 & 0.495 \\
\hline Alpha & 0.942 & 0.814 & 0.962 & 0.809 \\
\hline
\end{tabular}


TABLE 3

T-test comparison of the mean scores of instructors' and pilots' perceptions of gender-related pilot behaviour

\begin{tabular}{|c|c|c|c|c|c|c|c|}
\hline DEPENDENT VARIABLES & GROUPS & n & MEAN & $\begin{array}{l}\text { STANDARD } \\
\text { DEVIATION }\end{array}$ & $\mathbf{t}$ & $\begin{array}{r}\text { SIG. } \\
\text { (2-TAILED) }\end{array}$ & d \\
\hline \multirow[t]{2}{*}{ Flying proficiency } & Instructors & 93 & 103.452 & 18.720 & 2.203 & $0.029^{*}$ & 0.306 \\
\hline & Pilots & 93 & 97.011 & 21.079 & & & \\
\hline \multirow[t]{2}{*}{ Safety orientation } & Instructors & 93 & 38.828 & 6.355 & 1.786 & 0.076 & 0.262 \\
\hline & Pilots & 93 & 37.172 & 6.293 & & & \\
\hline
\end{tabular}

${ }^{*} p<0.05$

To prevent the problem of response bias, both positively and negatively worded statements relating to female pilots' flying proficiency and safety orientation were included. Examples of the wording of the two types of statements reveal the basic principles applied: 'Female pilots are less accident-prone than male pilots' (positive), 'Female pilots are more likely to lose control following a stall than male pilots' (negative), 'Male students learn piloting skills faster than female flight students' (negative) and 'Male pilots make more mistakes while learning to fly than female pilots' (positive).

The respondents were asked to rate statements using a five-point Likert-type scale to enable the measurement of the perceptions of the participants at an approximate interval level. All the items that consisted of negative statements towards female pilots were reverse-coded to produce a measure where high scores indicate positive perceptions and where low scores suggest negative perceptions regarding female pilots.

Vermeulen and Wilson (2002) reported high Cronbach alphas for flying proficiency (0.95) and safety orientation (0.86). The AGAQ has also been shown to have good reliability coefficients in cross-cultural samples. Wilson (2004) found that, in a sample of 182 American aviators, reliability ranged from 0.94 to 0.91 for flying proficiency and safety orientation. In a study of 1105 Australian pilots, Mitchell, Kristovics and Vermeulen (2006) found Cronbach alphas of 0.96 and 0.88 for the two scales, respectively. These high-reliability coefficients were retained in the present study (refer to Table 2).

\section{Research procedure}

A list of all the fixed-wing flight-training schools in South Africa was obtained from the SACAA. The schools for which contact details were available were approached by the researcher and they were asked to participate in the study on a voluntary basis. After the number of instructors at the participating schools was identified, 250 questionnaires were mailed to 65 flying schools. A covering letter accompanied the questionnaires, stating the purpose of the study, stressing that participation was voluntary and ensuring the confidentiality of the answers. Anonymity was also ensured, as respondents were not asked to indicate their names in the questionnaire. A total of 102 questionnaires was returned, of which 93 were usable. This represents a response rate of $37.2 \%$.
The data of the 93 commercial pilots in the control group were obtained from an existing database based on the convenience sample consisting of the 544 South African licensed pilots who participated in the initial development of the measuring instrument used in this study (Vermeulen \& Wilson, 2002). The random-numbers function of the Statistical Package for Social Sciences (SPSS) was used to identify and recover these 93 commercial pilots' information. The pilots all operated fixed-wing aircraft and flew for a cross-section of aviation companies that included three corporate organisations, seven charter companies, five airlines and the South African Air Force (military). The sample of 93 pilots included 36 airline pilots (38.7\%), 22 charter pilots $(23.7 \%), 31$ military pilots $(33.33 \%)$ and four corporate pilots (4.4\%). Refer to Vermeulen and Mitchell (2007) for detailed information regarding the sampling procedures that were followed to build the original database.

\section{Statistical analysis}

For the purposes of this study, descriptive, comparative and associational statistics were used to analyse the data. The statistical analyses were performed using SPSS for Windows, Release 14.

Descriptive statistics were included in order to condense and summarise the data and to describe the characteristics of both samples. Pearson's coefficient of mean-square contingency Phi was used to determine whether the samples were homogeneous in terms of their biographical characteristics. The internal consistency of the two scales of the AGAQ was assessed by calculating the Cronbach alpha coefficient for the data of the instructors and the data for the pilots. Levene's test of homogeneity and Box's M-test for homoscedasticity were administered to test for the assumption of the equality of variance across groups and for the assumption of the equality of covariance, which is required to conduct $t$-tests and multivariate analysis of variance (MANOVA), respectively, as recommended by Hair, Anderson, Tatham and Black (1998) and Tabachnick and Fidell (2007).

Students' t-tests for the analysis of variance were used in order to determine the differences between the mean scores of the different samples and the subgroupings in the instructors' sample with regard to their biographical characteristics and to their perceptions of gender-related pilot behaviour. Factorial MANOVA was used to uncover any possible relationships

TABLE 4

T-test comparison of the mean scores of the perceptions held by instructors with and without CRM training regarding gender-related pilot behaviour

\begin{tabular}{|c|c|c|c|c|c|c|c|}
\hline DEPENDENT VARIABLES & GROUPS & $n$ & MEAN & $\begin{array}{l}\text { STANDARD } \\
\text { DEVIATION }\end{array}$ & $\mathbf{t}$ & SIG. (2-TAILED) & d \\
\hline \multirow[t]{2}{*}{ Flying proficiency } & CRM training & 52 & 103.423 & 20.344 & 1.384 & 0.243 & - \\
\hline & No CRM & 41 & 103.488 & 16.682 & & & \\
\hline \multirow[t]{2}{*}{ Safety orientation } & CRM training & 52 & 38.346 & 6.756 & 1.604 & 0.209 & - \\
\hline & No CRM & 41 & 39.439 & 5.831 & & & \\
\hline
\end{tabular}


TABLE 5

MANOVA of flying proficiency and safety orientation with instructors' biographical characteristics as independent variables

\begin{tabular}{|c|c|c|c|c|c|c|c|}
\hline EFFECT & & VALUE & $\mathbf{F}$ & HYPOTHESIS DF & ERROR DF & SIG. & PARTIAL ETA SQUARED \\
\hline \multirow[t]{2}{*}{ Instructor rating } & Wilks's & & & & & & \\
\hline & Lambda & 0.947 & 1.050 & 3 & 152 & 0.383 & 0.027 \\
\hline \multirow[t]{2}{*}{ Education } & Hotelling's & & & & & & \\
\hline & Trace & 0.994 & 0.238 & 2 & 76 & 0.789 & 0.006 \\
\hline \multirow[t]{2}{*}{ Age } & Wilks's & & & & & & \\
\hline & Lambda & 0.968 & 0.420 & 6 & 152 & 0.865 & 0.016 \\
\hline \multirow[t]{2}{*}{ Instruction hours } & Wilks's & & & & & & \\
\hline & Lambda & 0.955 & 0.887 & 4 & 152 & 0.473 & 0.023 \\
\hline \multirow[t]{2}{*}{ Total flying time } & Wilks's & & & & & & \\
\hline & Lambda & 0.971 & 0.563 & 4 & 152 & 0.690 & 0.015 \\
\hline
\end{tabular}

between the biographical characteristics (independent variables) of the instructors and their perceptions of gender-related pilot behaviour, as recommended by Tabachnick and Fidell (2007). In cases where statistical significance was established, the practical significance of differences was challenged, in accordance with the recommendations by Cohen (1988) and Steyn (2000).

\section{RESULTS}

Before the main statistical analysis was undertaken, it was necessary to determine whether the characteristics of the two samples matched each other and to verify that both groups were comparable. The t-test results, computed for unequal variance, revealed that the mean age of the pilots and that of the instructors was approximately equal $(\mathrm{t}$ [164.24] $=1.923 ; \mathrm{p} \geq$ $0.06)$ and that both groups were similar in terms of their years of flying experience $(\mathrm{t}[178.11]=1.073 ; \mathrm{p}=0.29)$ and their total flying hours $(\mathrm{t}[161.60]=1.123 ; \mathrm{p}=0.26)$.

The Phi coefficient $(\varphi)$ was computed to test the strength of the relationships between sample identity and the biographical characteristics of the participants. No significant association was found between the sample grouping and gender $(\varphi=0.082 ; \mathrm{p}=$ $0.27)$, education $(\varphi=0.162 ; p=0.18)$ or pilot certification (type of licence) $(\varphi=0.049 ; \mathrm{p}=0.50)$. However, a smaller number of instructors had attended CRM training than pilots $(\varphi=0.345 ; p$ $\leq 0.001$ ). It was not possible to control for this variable in the composition of the pilot sample.

\section{Distribution of responses}

The responses of the two samples were first examined to determine whether the data were suitable for inferential statistical analysis. From the distribution of the responses set out in Table 2 , it is evident that the scores of the samples were approximately normally distributed. The assumption of normality requires that the key statistics, skewness and kurtosis are less than 2.5 times the standard error (Morgan \& Griego, 1998). The results of the One-Sample Kolmogorov-Smirnov Test of Normality confirmed that the scores for flying proficiency and safety orientation were normally distributed across both samples. The D values of the distributions of the scores for flying proficiency and safety orientation were $\mathrm{D}=0.557 ; \mathrm{p}=0.915$ and $\mathrm{D}=0.778 ; \mathrm{p}=0.580$ for the instructors and $\mathrm{D}=0.803 ; \mathrm{p}=0.539$ and $\mathrm{D}=0.700 ; \mathrm{p}=0.711$ for the commercial pilots.

The instructors' and the commercial pilots' scores yielded acceptable alpha reliabilities on both scales of the AGAQ. The Cronbach alpha coefficients of the two factors were 0.94 and 0.81 for the instructors and 0.96 and 0.81 for the commercial pilots. The alpha coefficients surpassed the minimum level of 0.70 recommended by Morgan and Griego (1998) for established scales. Levene's test of the equality of variance also indicated that the error variance of the dependent variables (flying proficiency and safety orientation) was equal across all categories (groups and subgroups) and that the assumption of homogeneity of variance was met. The $\mathrm{F}$ values for flying proficiency and safety orientation were $F=1.118 ; p=0.292$ and $F=0.028 ; p=0.867$ for the instructor and pilot groups and $\mathrm{F}=1.384 ; \mathrm{p}=0.243$ and $\mathrm{F}=$ 1.604; $p=0.209$ for the instructors with and without CRM training. The distribution and variance of the scores therefore displayed acceptable properties on both scales to satisfy the preconditions for continuing with inferential statistical analysis.

\section{Analysis of variance}

In order to achieve the aims of the research and test the hypotheses, analyses of variance were conducted. The two sample t-tests were used to determine the differences between the mean scores of the flight instructors and the commercial pilots with regard to each of the dependent variables, namely flying proficiency and safety orientation. This procedure was also followed to ascertain the difference in mean scores between instructors with CRM training and instructors without CRM training with regard to each of the dependent variables. Because the hypotheses were stated in non-directional terms, the twotailed tests were calculated for statistical significance.

The outcome of one of the t-tests presented in Table 3 indicated a significant difference $(t[184]=2.203 ; \mathrm{p}<0.05)$ between the two main groups' perceptions of female pilots' flying proficiency. The mean score $(\bar{X}=103.452)$ for the instructors was higher than the mean score $(\bar{X}=97.011)$ for the commercial-pilot sample. Although significant differences were found between the perceptions held by the instructors and those held by the commercial pilots, it should be noted that the practical significance $(d=0.306)$ was very small and that the practical implications of the finding are negligible. There was no statistically significant difference $(t[184]=1.786 ; p=0.076)$ between the perceptions held by the two samples concerning female pilots' safety orientation. The hypothesis $\mathrm{H}_{1}$ of difference between samples can therefore not be accepted at a $95 \%$ level of confidence.

From Table 4, it is evident that the CRM training of the flight instructors was not related to their perceptions of gender-related pilot behaviour. The two subgroups' perceptions did not differ significantly in terms of their views of female pilots' flying proficiency $(t[91]=1.384 ; \mathrm{p}=0.243)$ or safety orientation ( $\mathrm{t}$ [91] $=1.604 ; \mathrm{p}=0.209)$. Hypothesis $\mathrm{H}_{2}$ was not supported by the results, as the mean scores of both subgroups in the instructors' sample were approximately the same for each factor.

A factorial MANOVA was performed to ascertain whether the vector means of the different subgroups in the instructors' sample differed from one another with regard to genderrelated pilot behaviour. In order to test the assumption of the 
equality of the variance-covariance matrices of the subgroups, Box's test of the equality of covariance matrices was used. The results indicated that the observed covariance matrices of the dependent variables were equal across all subgroups and that the assumption of equality was not violated $(\mathrm{M}=18.04 ; \mathrm{F}=0.516$, $\mathrm{p}=0.982)$.

The results of the five-factor MANOVA depicted in Table 5 indicated that the biographical characteristics of instructors did not relate significantly to their perceptions of female pilots' flying proficiency or safety orientation. The Wilks's Lambda and Hotelling's Trace values and associated F values that were obtained indicated that there were no statistically significant differences in the vector means of the different subgroups of each of the five biographical variables. These findings did not support the premise that there are significant relationships between the biographical characteristics of flight instructors and their perceptions of gender-related pilot behaviour.

\section{DISCUSSION}

For decades, female aviators have had to defy social prejudices despite having achieved remarkable feats of skill and endurance. 'Men do not believe us capable,' the famed aviatrix Amelia Earhart once remarked to a friend. 'Because we are women, seldom are we trusted to do an efficient job' (Moolman, 1981, p. 7).

The main objectives of the study were to compare flight instructors' and commercial pilots' perceptions of genderrelated pilot behaviour and to explore the relationship between the biographical characteristics of the instructors and their perceptions of female-pilot behaviour.

The results of this study reveal that the instructors hold a more positive perception of female pilots' performance than the commercial pilots. Although the instructors and commercial pilots differ significantly in terms of their perceptions of female pilots' flying proficiency, the difference between the two mean scores was too small to be of practical significance. With regard to their perceptions of female pilots' safety orientation, the instructors and commercial pilots did not differ significantly.

Although this study shows no meaningful differences between the perceptions of the instructors and commercial pilots, it was remarked during the examination of the distribution of the responses within groups that a noticeable number of the instructors expressed positive judgements about female pilots.

Based on the description by Gregory (2004) of the percentage that constitutes low and high-scoring groups, the number of respondents in the total sample $(n=186)$ who scored at the 33rd percentile and below and the number of those who scored at the 66 th percentile and above were calculated.

The ratio of instructors in the low-scoring versus instructors in the high-scoring groups was 28 to 37 for flying proficiency and 31 to 41 for safety orientation. These proportions show that a relatively higher number of instructors in the present sample held positive perceptions with regard to female pilots' flying proficiency and safety orientation. This result is promising, since the first point of contact for female pilots is usually with their instructors. Instructors' more positive perceptions might therefore enhance the learning situation for trainee female pilots (Kristovics, Mitchell, Vermeulen, Wilson, \& Martinussen, 2006). The present survey does not reveal statistically significant differences $(p>0.05)$ between the perceptions held by instructors with CRM training versus those held by instructors withou CRM training. Both subgroups display similar perceptions with regard to female pilots' flying proficiency and safety orientation. This study can therefore show no relationship between the CRM training received by instructors in this sample and their perceptions of the flying proficiency and safety orientation of female pilots. This finding may be attributed to a number of factors.
Firstly, it seems very unlikely that no transfer of knowledge occurred during the training of the instructors in CRM. It may be that the CRM training that they attended did not address the psychology of differences and the management of diversity sufficiently to have a meaningful effect. A review of the instruction manuals and syllabi of a few current CRM programmes presented by airlines and by individual training institutions confirms a lack of gender-related and diversitymanagement content.

Secondly, it is also possible that the regulatory requirement that all pilots, from private student pilots to pilots training for a commercial pilot's licence, must be trained in human factors plays a role. All instructors therefore have thorough training in human-factors theory and practice and are responsible for the training and education of their students to acquire the knowledge, skills and attitudes required for safe flight behaviour (Droog, 1998; O'Hare, 1999; Severin \& Antersijn, 1998). To meet the needs of the aviation system, instructors are supposed to align their personal perceptions and behaviour with acceptable human-factor theory and practices (Davey, 2004). This may encourage uniformity among instructors in respect of behaving in a manner consistent with human-factor principles.

Finally, one can deduce from the results of the five-way factorial MANOVA that the attitudes of the instructors towards female pilots are not influenced by specific biographical variables. The instructors' rating, level of education, age, hours of tuition (instruction) and total flying time do not appear to be related to their perceptions of female pilots' flying proficiency and safety orientation.

These results are supported by the research findings of Wilson (2004), who considered a variety of factors as the potential basis for the occurrence of particular attitudes (whether positive or negative) with regard to the flying proficiency and safety orientation of female pilots. She investigated factors such as pilot certification, education, position, age, flying time, opportunity to fly with the opposite gender, nationality and gender. The data on 530 South African and 184 American pilots were used to determine the main and interaction effects of the biographical variables. After extensive analysis, she found that the only variable that had significant impact on these genderrelated attitudes was gender itself. Wilson (2004) also found that, compared to male pilots, female pilots were more positive in their responses to both flying proficiency and safety orientation.

\section{Limitations}

The small number of females in the instructor group (nine) and the pilot group (five) restricted the possibility of exploring the effect of gender on the instructors' and the pilots' perceptions of female pilots' flying proficiency and safety orientation. The fact that so few responses could be obtained from female instructors and female pilots should be regarded as a limitation not only of the current study but, for the foreseeable future, also of future research. This limitation coincides with data received from the SACAA, which reflect a much smaller proportion of licensed female pilots and female instructors (6.1\%) in the South African pilot population compared to male counterparts (SACAA, 2007).

Opportunities for male instructors to fly with female pilots are also considered an independent variable in this study to establish whether professional exposure reduces negative perceptions of female pilots. Social psychologists have long studied the concept of exposure to or experience with members of a particular group as a means of changing stereotypes and attitudes positively and breaking down barriers between groups (Allport, 1954; Johnson \& Johnson, 2003). Unfortunately, most of the male instructors $(85.5 \%)$ and male pilots $(80.6 \%)$ indicated that they never or rarely have an opportunity to fly with the opposite gender. The responses of the 83 male instructors to this variable are as follows: 
two (2.3\%) stated that they had 'never' flown with a woman, 69 $(82.1 \%)$ stated that they 'rarely' do so, $11(13.2 \%)$ stated that they 'sometimes' do so, one (1.2\%) said that he 'often' does so and one $(1.2 \%)$ said that he 'mostly' does so.

By contrast, the nine female instructors all selected the 'mostly' category, indicating that they have ample opportunities to fly with the opposite gender. Consequently, there were not enough numbers of respondents for each cell to statistically scrutinise the relationship between opportunity to fly with the opposite gender and perceptions about female pilots' flying proficiency and safety orientation. Because of the small number of female pilots in South Africa, male instructors will continue to have a disproportionately low chance of flying with female pilots in the future.

Furthermore, given the limited size of the flight instructors' sample, additional research is needed to confirm the results of the present study and support the generalisation of the findings to the overall flight-instructor populations of South Africa and to make the aviation industry aware of the challenges of diversity. According to Turney and Bishop (2004), an awareness of diversity in the aviation industry is important in improving the aviation operational culture and promoting effective teamwork among flight personnel. They suggested that check pilots and instructors receive regular and current information about research regarding gender differences. They regard instructors as key personnel in fostering positive gender-related attitudes and provide examples of specific instructor behaviour that enhances the learning relationship between instructors and student pilots of the different sexes. To facilitate $a b$ initio pilot training and ensure a positive learning environment, Turney and Bishop have suggested the following:

Instructors should consciously encourage both sexes to succeed, elicit responses equally, and be aware of attitudes, tone of voice and choice of language. They should dispel stereotypes and select anecdotal material with which both women and men can relate. Expertise in interpersonal relationships has become as crucial as recurrent training on aircraft systems.

(Turner 2004, p. 71)

Continued research on diversity in aviation settings is needed to understand key concepts and fundamental issues associated with stereotyping, attitudes and prejudices. Research with regard to gender-based matters in aviation holds significant advantages for this sector:

- Firstly, understanding how gender-related stereotypes and attitudes are formed with application to the aviation industry may allow for conceptual modelling. This has both an academic and a real-world benefit for the field of aviation psychology in that it allows a better understanding of how opinions are formed in the first place, especially with regard to the roles expected of the members of the opposite gender and their perceived abilities (Spertus, 1991).

- Secondly, it is also important to understand the nature of professional socialisation - how individuals take on the values and attitudes of the particular group to which they belong. Knowledge of studies in social psychology (Johnson \& Johnson, 2003) regarding concepts such as socialisation, group membership, social interdependence and conformity can be of great value to aviation psychologists in understanding group identity, group behaviour and the dynamics of professional identity in aviation.

- Thirdly, knowledge of the relationship between genderrelated attitudes and crew behaviour can help to create a gender-sensitive, multi-crew environment (Turney, 1995; Turney \& Bishop, 2004) that supports positive interaction among diverse flight and cabin-crew members. Positive interactions in two-gender crews are necessary to advance productivity and safety, especially in irregular operations (Turney, 1995).

- Fourthly, knowledge of aviators' perceptions with regard to gender-related pilot behaviour is also important in developing training material that is better targeted. Topics such as gender differences, gender-based stereotyping, hostile and benevolent sexism, occupational gender segregation and the implications of a 'stereotype threat' for performance can add immense value to existing curricula. This applies to both human-factor training and CRM training for instructors and for commercial and airline pilots alike.

- Fifthly, in order to use the diverse populations of South Africa effectively and to absorb more female pilots into the industry successfully, it is essential that sources of gender bias, prejudice and discrimination be identified. To address possible negative perceptions, managers at flight schools, airlines and fixed-base operations must commit themselves to implementing organisational practices that will curb negative stereotyping and discrimination.

Finally, it is perhaps good to conclude with the following caveat from Mitchell et al. regarding this topic:

The aviation industry, in an attempt to encourage women to take up flying as a career, needs to address many latent issues that provide disincentives to women. Issues that need to be addressed include the recognition of differences between females and males in respect of training from the ab initio stage through licensing and command training and evaluation in airlines.

(Mitchell 2006, p. 55)

\section{ACKNOWLEDGEMENTS}

This article is part of a research project on gender issues in aviation coordinated by Prof. Dr Leopold P. Vermeulen (University of Pretoria) and Dr James I. Mitchell (University of Western Sydney), in conjunction with Dr Alexandra Kristovics (University of Western Sydney) and Prof. Dr Monica Martinussen (University of Tromsø).

The researcher would like to thank Ulrich le Kay, previously research assistant at the Department of Human Resources Management, University of Pretoria, for his support in collecting and capturing the data.

\section{REFERENCES}

Allport, G.W. (1954). The nature of prejudice. Reading: Addison Wesley.

Baker, S.P., Lamb, M.W., Grabowski, J.G., Rebok, G., \& Li, G. (2001). Characteristics of general aviation crashes involving mature male and female pilots. Aviation, Space, and Environmental Medicine, 72(5), 447-452.

Barker, D. (1999). Women pilots in operational combat: An emotive issue, Part 1. Salut, 8, 30-34.

Bartsch, J., \& Hawkins, R.M.F. (1996). The influence of sex, attractiveness and qualifications on hiring practices in aviation. In B.J. Hayward \& A.R. Lowe (Eds.), Applied aviation psychology: Achievement, change and challenge. Third Australian Aviation Psychology Symposium, n.d. 1995 (pp. 343350). Aldershot: Ashgate.

Cohen, J. (1988). Statistical power analysis for behavioral sciences. (2nd edn.). Hillsdale: Lawrence Erlbaum.

Davey, C.L. (2004). The impact of human factors on ab initio pilot training. Gender, Work and Organization, 11(6), 627-647.

Davey, C.L., \& Davidson, M.J. (2000). The right of passage? The experiences of female pilots in commercial aviation. Feminism and Psychology, 10(2), 195-225.

Droog, A. (1998). Developing the pilot's skills and attitudes. In K. Goeters (Ed.), Aviation psychology: A science and a profession (pp. 147-156). Aldershot: Ashgate.

Fischer, U., \& Orasanu, J. (1999). Confronting the boss indirectly: Study of cockpit crews finds copilots use 'hints' to correct captains. Research News \& Publications Office. Georgia Institute of Technology. Retrieved 25 April, 2002, from http:// gtresearchnews.gatech.edu/newsrelease/CREW.html.

Frazier, D.A. (2000). Training and instruction. Controlling pilot error series, Vol. 5, New York: McGraw-Hill. 
Glick, P., \& Fiske, S.T. (2001). An ambivalent alliance: Hostile and benevolent sexism as complementary justifications for gender inequality. American Psychologist, 56, 109-118.

Gray, J. (1992). Men are from Mars, women are from Venus: The classic guide to understanding the opposite sex. New York: HarperCollins.

Gregory, R.J. (2004). Psychological testing: History, principles, and applications. (4th edn.). Boston: Pearson.

Hair, J.F., Anderson, R.E., Tatham, R.L., \& Black, W.C. (1998). Multivariate data analysis. Englewood Cliffs: Prentice-Hall.

Helmreich, R.L., \& Merritt, A.C. (1998). Culture at work in aviation and medicine: National, organizational and commercial influences. Aldershot: Ashgate.

Johnson, D. (1995). Cultural differences: Flight deck reality and problems. In B.J. Hayward \& A.R. Lowe (Eds.), Applied aviation psychology: Achievement, change and challenge. Third Australian Aviation Psychology Symposium, n.d. 1995 (pp. 191194). Aldershot: Ashgate.

Johnson, D.W., \& Johnson, F.P. (2003). Joining together group theory and group skills. (8th edn.). Boston: Allyn and Bacon.

King, R.E., Retzlaff, P.D., \& McGlohn, S.E. (1997). Female United States Air Force pilot personality: The new right stuff Military Medicine, 162(10), 695-697.

Kristovics, A., Mitchell, J., Vermeulen, L.P., Wilson, J., \& Martinussen, M. (2006). Gender issues on the flight-deck: An exploratory analysis. International Journal of Applied Aviation Studies, 6(1), 99-119.

McCarthy, E., \& McGinn, A. (1995). Organisational culture, job satisfaction and work stress: The case of Irish women pilots. In N. McDonald, N. Johnston \& R. Fuller (Eds.), Applications of psychology to the aviation system. Proceedings of the 21st Conference of the European Association for Aviation Psychology (EAAP). Vol. 1, (pp. 81-90). Aldershot: Ashgate.

McFadden, K.L. (1996). Comparing pilot-error accident rate of male and female airline pilots. Omega, International Journal of Management Science, 24, 443-450.

Mitchell, J., Kristovics, A., \& Vermeulen, L.P. (2006). Gender issues in aviation: Pilot perceptions and employment relations. International Journal of Employment Studies, 14(1), $35-59$.

Moolman, V. (1981). Women aloft. Alexandria: Time-Life.

Moore, P.J., Lehrer, H.R., \& Telfer, R.A. (1997). Instructor perspectives on learning in aviation. Paper presented at the Ninth Annual International Symposium on Aviation Psychology, Columbus, $\mathrm{OH}$.

Morgan, A.G., \& Griego, O.V. (1998). Easy use and interpretation of SPSS for Windows: Answering research questions with statistics. London: Lawrence Erlbaum.
O'Hare, D. (1999). Safety is more than accident prevention. Risk factors for crashes and injuries in general aviation. In D. O'Hare (Ed.), Human performance in general aviation, (pp. 265-279). Aldershot: Ashgate.

SACAA. (2007). South African licensed pilots' information. [Statistics per license by gender, XLS]. Licensing office of the South African Civil Aviation Authority (SACAA), July 27, 2007.

Severin, K.H., \& Antersijn, P.A. (1998). Human factors training in aviation: The trainee. In K. Goeters (Ed.), Aviation psychology: A science and a profession, (pp. 157-161). Aldershot: Ashgate

Sitler, R. (2004). Gender differences in learning to fly. In M.A. Turney (Ed.), Tapping diverse talents in aviation: Culture, gender, and diversity, (pp. 77-88). Aldershot: Ashgate.

Sitler, R., Turney, M.A., \& Wulle, B. (1996). Attitudes reflective of gender-based issues in the aviation and transportation workplace. In B.J. Hayward \& A.R. Lowe (Eds.), Applied aviation psychology: Achievement, change and challenge. Third Australian Aviation Psychology Symposium, n.d. 1995 (pp. 332342). Aldershot: Ashgate.

Spertus, E. (1991). Why are there so few female computer scientists? Retrieved 21 March, 2002, from http://www.inform.umd. edu/EdRes/Topic/WomensStudies/Computing/Articles+ Research.

Steyn, H.S. (2000). Practical significance of the difference in means. South African Journal of Industrial Psychology, 26(3), $1-3$.

Tabachnick, B.G., \& Fidell, C.S. (2007). Using multivariate statistics. (5th edn.). Boston: Allyn and Bacon.

Turney, M.A. (1995). Women's learning and leadership styles: Impact on CRM. In N. McDonald, N. Johnston \& R. Fuller (Eds.), Applications of psychology to the aviation system. Proceedings of the 21st Conference of the European Association for Aviation Psychology (EAAP). Vol. 1 (pp. 262-268). Aldershot: Ashgate.

Turney, M.A., \& Bishop, J.C. (2004). Women's learning and leadership styles: Implications for air crews. In M.A. Turney (Ed.), Tapping diverse talents in aviation: Culture, gender, and diversity, (pp. 61-75). Aldershot: Ashgate.

Vermeulen, L.P., \& Mitchell, J.I. (2007). Development and validation of a measure to assess perceptions regarding gender-related behavior. The International Journal of Aviation Psychology, 17(2), 75-96.

Vermeulen, L.P., \&Wilson, J. (2002). The measurement of perceptions with regard to gender-based issues in aviation. Unpublished research report. University of Pretoria, Pretoria, South Africa.

Wilson, J. (2004). Gender-based issues in aviation, attitudes towards female pilots: A cross-cultural analysis. Unpublished doctoral thesis, University of Pretoria, Pretoria, South Africa. 